\title{
The Influence of Structural Conditions and Cultural Inertia on Water Usage and Landscape Decision-Making in a California Metropolitan Area
}

\author{
Madhusudan Katti ${ }^{1, *}$ () , Andrew R. Jones ${ }^{2}$, Derya Özgöç Çağlar ${ }^{3}$, Henry D. Delcore ${ }^{4}$ and \\ Kaberi Kar Gupta ${ }^{5}$ \\ 1 Department of Forestry and Environmental Resources, North Carolina State University, \\ 5223 Jordan Hall Addition, P.O. Box 8008, Raleigh, NC 27695, USA \\ 2 Department of Sociology, California State University, Fresno 5340 N, Campus Dr. M/S SS97, Fresno, \\ CA 93740, USA; anjones@csufresno.edu \\ 3 Ostim Teknopark Inc., 100. Yıl Bulvarı OFIM İş Merkezi Kat: 10 No: 99/12, OSTIMM Ankara 06370, Turkey; \\ derya.caglar@gmail.com \\ 4 Department of Anthropology, California State University, Fresno 5245 N, Backer Ave. M/S PB20, Fresno, \\ CA 93740, USA; hdelcore@csufresno.edu \\ 5 Biodiversity Lab, North Carolina Museum of Natural Sciences, 11 West Jones Street, Raleigh, NC 27601, \\ USA; lorises@gmail.com \\ * Correspondence: mkatti@ncsu.edu; Tel.: +1-919-515-8638
}

Received: 29 July 2017; Accepted: 25 September 2017; Published: 27 September 2017

\begin{abstract}
Urban development and planning are increasingly centered on matters of sustainability, balancing economic development with ecosystem services and biological diversity within urban environments. In addition to these institutional and structural factors, the decision-making process within individual households must be understood to address rising concerns about water use. Therefore, individual characteristics and preferences that influence the use of water also warrant examination. In response to a survey of occupants of single-family residences in the Fresno Clovis Metropolitan Area of California, contextual interviews and focus group interviews with a homeowner sub-sample, we find evidence of an interplay of social—structural, institutional, and cultural factors involved in influencing individual water use behaviors and landscape decision-making. The complexity of residential behaviors and decision-making poses some potential issues with regards to the interactions between individual households and institutional actors in matters of water usage and landscaping, as residents surveyed indicate relatively little confidence in institutions and groups to make wise water policy decisions. We conclude that the promotion and implementation of sustainable water use practices will require not only environmental education for the citizenry, but also a tailoring of information for environmental educational initiatives that address the particularities of individual neighborhoods and communities.
\end{abstract}

Keywords: urban sustainability; California; landscape decision-making; urban environment; water use behaviors; social—ecological systems

\section{Introduction}

The availability and use of water are issues of increasing concern for urban environments in arid regions, in particular the American Southwest. Kundzewim [1] (p. 291) states that in water-stressed areas, any improvement in efficiency of water use is valuable. Urban development and planning are increasingly centered on matters of sustainability, balancing economic development with ecosystem services and biotic structures within urban environments [2-4]. Water is one of the key natural resources for urban development and the sustainability of biotic structures [5-9], and thus requires 
an integrated and holistic approach to its development and management [1]. Academic research has taken into account the interrelationships between the human social and natural spheres using models that address complexity, such as the socio-ecological systems (SES) approach [10]. The SES approach provides the framework used in the Urban Long-Term Research Area-Fresno and Clovis Ecosocial Study (ULTRA-FACES) in examining the dynamic interactions between those spheres with regard to water usage and its impacts on biodiversity in the Fresno/Clovis Metropolitan Area (FCMA).

In this paper we address a core question of the ULTRA-FACES project, by analyzing individual human characteristics and preferences that influence the use of water in the FCMA. We employ a mixed methods approach, combining the strengths of both qualitative and quantitative methods of collecting data: we first sent surveys to selected individual households in each region (Fresno, Clovis and county islands) based on random selection of plot points using ArcGIS Desktop software (ESRI, Redmond, CA, USA); we then visited a subset of these homes for detailed interviews and direct observation of individual behavior using techniques of ethnographic and behavioral analyses; we also conducted focus group interviews with homeowners representing three income groups.

\section{Theoretical Context}

Modern urban areas serve as laboratories for observing the interplay between social-ecological relationships [11,12]. Landscaping and irrigation in residential areas are a product of a plethora of environmental conditions, the homeowners' cultural preferences, socioeconomic status, neighborhood dynamics, as well as zoning laws, market conditions, city policies, and county/state/federal government regulations. Since land and water management are key determinants of habitat for other species, urban biodiversity is strongly driven by the outcome of interactions between these variables [13].

Research to date supports the generalization that socio-economic status is linked to resource consumption, in that the greater the level of affluence, the higher the rate of natural resource consumption [14-20]. As this was an exploratory study, the data gathered could potentially be explained from several different theoretical frameworks. The drivers of outdoor water consumption at the individual household level have been broadly analyzed. In addition, people tend to increase or reduce their purchases of goods and services based on affordability [21,22]. However, as both a good and a service, water is usually priced at a low rate in industrialized and post-industrial countries as it is deemed essential to human survival [14]. Such analyses indicate that the market price of water reflects the delivery of service rather than being for the resource itself [23-26]. The issue of water pricing raises the question of how a municipality may effectively reduce residential water use. Graymore and Wallis [8] (p. 84) stated that mandatory water restrictions show more consistent reduction in water use compared to voluntary restrictions which show more variable results [26]. Thus, water pricing may reduce water consumption under certain conditions $[8,17,27]$, but most municipal water departments avoid water pricing policies that could encourage conservation [28]. Some research indicates that since rate structure is not fully understood by the households and the bill is not a large proportion of the household budget, the cost of water is negligible for budgetary decision-making in most households [8,15]. In addition, households often have limited control over water consumption as structural factors such as home design and pre-existing residential landscapes require a certain level of water use for maintenance $[29,30]$. Such factors may over time intensify water usage. The structuring of landscapes and the human-built environment may create a treadmill of consumption [31] wherein people consume more and more material resources without any real gains in human satisfaction or well-being.

The preceding discussion focuses on structural models as explanations of outdoor water use. Such structural models neglect the status honor [32,33] conferred upon individuals for engaging in conspicuous consumption of resources $[34,35]$. As a more cultural explanation of water usage, people form themselves into groups or communities in part on the basis of status honor associated with consumption (with different standards of living being associated with a particular status). In addition 
to social status, consumption is assumed to further the attainment of human contentment and overall well-being [36-38]. Thus, people will intensify levels of consumption in periods of prosperity, as this provides them a visible way of demonstrating nurturing behavior towards their families [36].

As another theoretical framework, this sense of comfort and well-being relates to social psychology models of consumption, but with a different outcome in terms of consumption. Such models assume that the more affluent live in newer structures that are more energy and resource efficient, and are more highly educated, which should lead to more environmentally-minded behavior [39]. As a result, affluence correlates with decreased water usage $[16,40]$. However, some studies indicate education and environmental awareness are not always linked to behavior [41] as affluence may lead to increased water usage, given that wealthy individuals, in establishing their distinct identity from other social classes, consume more expensive water features and services (and consume more water) by virtue of their buying power [42]. Related to social-psychological explanations is the concept of cultural inertia, which posits that any change in behavior on the part of individuals or groups may be hindered or enabled based on perceptions of whether some social transformation is already taking place [43] or whether existing social-structural arrangements facilitate or deter efforts at change [44,45]. With respect to social-structural arrangements, on a broader time scale, this cultural inertia may be connected to the concept of landscape legacy, which involves the long-term impacts of anthropogenic events and processes on an ecosystem's structure, composition, and/or function [46,47]. Historically, Fresno's city limits have expanded to the north and east from the urban core, involving the conversion of agricultural lands and orchards into suburban neighborhoods and shopping centers, and intersecting the city with neighboring Clovis. Prior to this conversion, the area of the San Joaquin Valley in which the FCMA is situated was mostly grasslands and riparian woodlands, meaning the agricultural development of the Valley is a recent disturbance, and the suburbanization of agricultural lands surrounding the FCMA an even more recent disturbance [48]. Given this history, it is possible that the landscape decision-making of property owners from several decades ago may have more of an impact on contemporary residential landscapes than the decisions made by current occupants $[49,50]$.

Outdoor water usage may be subject to factors in personal identity selection [51,52]. Consumption, according to this theoretical model, is associated with the sense of self and personality. Another factor related to consumption and identity is the Diderot effect [53,54]. Here, outdoor water usage is tied into the standard of consumption by which an individual seeks to establish a particular social identity-as people consume new artifacts, existing acquisitions need to be replaced so as to maintain a "matched set" [53]. The Diderot effect moves the standard of consumption upward, potentially increasing water consumption as individuals seek to display a more cultured, affluent identity.

A focus on status striving, conspicuous consumption and social-psychological processes that favor consumption can produce some contradictory expectations. Recent work in urban ecology suggests that models built on the influence of education and income alone may not provide enough nuance to understanding residential landscape choices [55-58]. Grove et al. [56] use the Claritas PRIZM categorization to show that lifestyle behavior was the best predictor of vegetation cover on both private lands and public rights-of-way. Of private lands, they conclude that, "household land management decisions, influenced by a household's desire to assert its membership in a given lifestyle group and to uphold the prestige of the household's neighborhood, best predicts variations in vegetation cover on private lands" [56] (p. 592). They do not suggest discarding a focus on social stratification, but argue that adding lifestyle behavior can improve results: "Thus, social stratification is a better predictor of the possibility for vegetation, but lifestyle behavior is a better predictor of the vegetation cover that is realized" [56] (p. 593). Larsen and Harlan [55] suggest another avenue for breaking down easy generalizations about social stratification, showing that status concerns [34] and self-presentation [59] are more relevant to the front yard while individual preference reigns in the backyard: "we propose that in the front yard, form follows fashion while in the backyard, form follows fantasy" [55] (p. 98).

Robbins [57] makes one of the most ambitious recent attempts at contextualizing residential landscaping choices as a way out of the contradictions of existing frameworks. Robbins starts with 
the observation that turfgrass managers of relatively high income and education, though predicted in the literature to be more environmentally conscious, use more chemicals on their lawns than those with less income and education. To explain this seeming contradiction, Robbins criticizes frameworks dominated by emphasis on choice, culture, demand and sovereign human action. Instead, he argues that we need to see the lawn as a political and economic network in which lawn chemical firms, communities, individuals and lawns themselves "are chained together in such a way that they tyrannize one another" [57] (p. 14) to enforce a regime of high-input lawn care. For example, Robbins explores the informal community norms of what turn out to be highly regulated neighborhoods; these norms promote high-input maintenance of lawns, even as the lawn manager himself expresses anxiety about the amount of chemicals he or his lawn care company are applying. With this study, we analyze the different potential social factors that may be driving outdoor residential water usage such as individual's socioeconomic status, status honor, lifestyle, sense of self and personality as well as water pricing and structural conditions.

\section{Materials and Methods}

The FCMA is the largest urban area within the San Joaquin Valley and is the fifth largest metropolitan area in California. The City of Fresno was one of the few major cities in the country that, up until 2013, charged a flat rate for residential water use before implementing water metering in compliance with a federal mandate (the City of Clovis metered residential areas in 1910). Prior to metering, approximately $51 \%$ of city water in Fresno was for residential use, with an estimated $70 \%$ of that consumption going towards landscape irrigation. The estimated per capita daily water consumption in Fresno prior to metering was circa $1245 \mathrm{~L}$ [60]. California experienced the worst drought on record during 2010-2015 [61], forcing the Governor to declare a state of emergency in 2015, and mandating municipalities to reduce water use by $30 \%$, based on consumption patterns in each water district from the summer months of 2014-a goal attained by the City of Fresno. This study provides an opportunity to understand the impact of individual decision-making on water use just before drought and major policy decisions (water metering and declaration of the state of emergency) imposing severe restrictions on water availability.

This study is part of the core of the ULTRA-FACES project, which addresses the significance of water as a key resource shaping regional patterns of landscape and biodiversity in the Fresno-Clovis Metropolitan Area. We collected data on birds [62] and trees [63] (representing biodiversity) and social factors (individual household water usage). These studies of urban biodiversity found that both home property value and irrigation levels were strongly positively correlated with tree species diversity [63] and bird species diversity [62].

We derived social data through a combination of a mail questionnaire, site visits and focus group interviews of a subset of the mail survey respondents. We use a mixed method approach for this study to acquire and analyze both qualitative and quantitative data. This paper focuses on analysis of the social data in order to illuminate the role of individual preferences and characteristics in outdoor water use.

\subsection{Sampling}

As noted above, data collection for the ULTRA-FACES study involved field surveys of the species diversity and abundance of birds [62] and trees [63], and surveying households via a mail questionnaire, conducting site visits, and performing focus group interviews. All of these were implemented using a common sampling grid system covering the FCMA established by the Fresno Bird Count (FBC) [62], consisting of 418 map points.

\subsection{Social Survey}

Selection of households for the social survey involved a random selection of approximately $18 \%$ of the FCMA Bird Count Map points. Using ArcGIS's random selection tool and defining the 
region under study by the proportion of geographic territory encompassing each governmental entity, we selected 20 of 113 county sites, 45 of 255 Fresno metropolitan sites and 10 of 50 Clovis metropolitan sites (Figure 1). Factors for selection were: housing density (at least 10 addresses within $100 \mathrm{~m}$ of the center of the FBC site), median income by census tract, and municipal/county boundaries (accounting for socio-economic status and water policies as factors affecting water usage as indicated in the study's model).

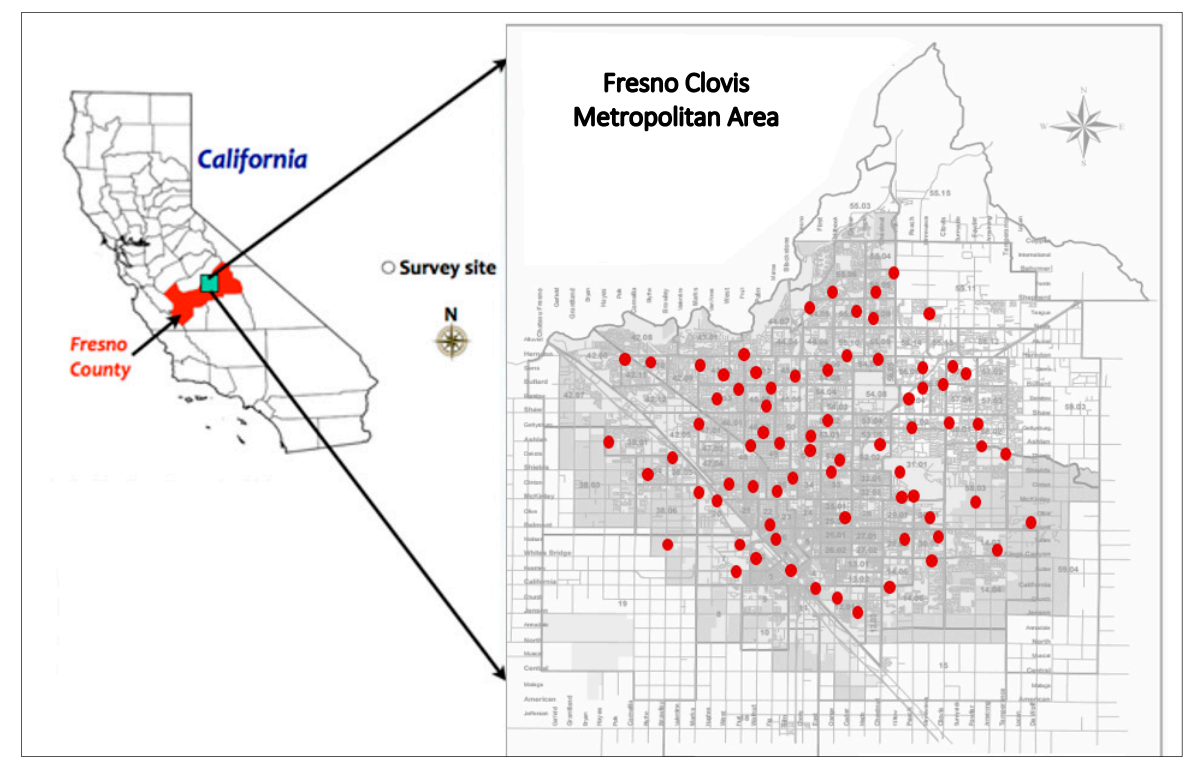

Figure 1. Map of Fresno and Clovis metropolitan area with sampling locations in red.

This sampling method resulted in 74 sites selected, after excluding sites that lacked the required housing density (i.e., sites that centered on parking lots, park areas, and other non-residential areas). ArcGIS generated a set of 2393 addresses for the 74 sites. Each FBC site had an alpha-numeric designation, and each address had associated map coordinates (on an $X-Y$ axis).

To ensure confidentiality for potential respondents, each address receiving the social survey was identified by the FBC site alpha-numeric designation, along with a letter designation corresponding to the address' location on the $X-Y$ axis. We attained a survey sample of approximately 750 households with each FBC site selected having at least 10 addresses associated with it. The self-addressed, stamped envelope and the survey had the identifier printed on them, allowing researchers to identify from which survey sites they had received responses. One limitation of mail surveys involves deriving a potentially loaded sample, as those with higher educational attainment are more likely to complete such surveys. While we acknowledge that educated people are more motivated to participate in surveys [64] (p. 210), we chose mail surveys for data collection owing to logistical and budgetary constraints of the study.

\section{Questionnaire Contents}

The mail questionnaire consisted of 38 questions (see Supplementary Material, Table S1) in four areas of inquiry: (1) demographic data; (2) outdoor water use; (3) water policies in the neighborhood and (4) decision-making involving water use. The mail questionnaire included questions about housing, education, income, age, racial category, yard attributes and maintenance choices, budget for watering, water consumption decisions, metering and water use restrictions. Most of the question responses were structured as either yes/no or intervals. In addition, there were questions designed to specify respondents' level of agreement or disagreement on a symmetric agree-disagree scale for a series of statements (see Supplementary Material for details). We used IBM SPSS statistics software 
version 24 (IBM Corp., Armonk, NY, USA) for the analysis, employing chi square as well as frequency and descriptive statistics on the data.

\subsection{Site Visits}

In order to deepen the analysis and open up the information that is not readily available with mail questionnaires, we conducted site visits of 10 of the survey respondents' homes. We selected homeowners because we assumed that they would have more control over landscaping decisions than renters, and hence provide a better window on attitudes and actions toward domestic landscape water use. We chose a relatively educated group (between community college attendance and a four-year degree) from the sample in order to test some possible relationships among education and resource usage. Also, willingness to participate was an important issue for this preliminary study as it is higher among the more educated. As an incentive to participate, all survey respondents who fit the criteria were contacted by mail and offered a $\$ 50$ gift card for allowing researchers to view their landscape and conduct a two-hour interview. This recruitment process resulted in ten site visit participants.

The site visits involved contextual interviews during which two researchers visited the homeowner at home to discuss domestic landscape water use. On site, the researchers toured the homeowner's yard with them, asking follow-up questions related to the original survey. The participants were given wide latitude in determining the direction of the interview (encouraging participants to provide their own narrative in discussing household water use and landscape development), but in the end, every participant was asked to respond to the same questions while showing the researchers the evidence, on the ground, of their reported behaviors. Questions posed during the site visit revolved around whether and how the landscape was planned, sources of information and advice, and criteria for deciding on plantings. On each site visit, the interviewers chose at least one planting for more detailed questions, focusing on water-intensive, drought-resistant and new plantings. For these detailed explorations, we asked each resident about fertilizer and pesticide use in regards to the planting, its water requirements and its value in attracting or repelling animals. A final set of questions probed the resident's knowledge of and regard for municipal water use policies, including knowledge of impending metering. If the resident employed a landscape service or had some other person caring for their yard or water system, the interviewers explored with them the division of labor between themselves and the other actor(s) with regard to water use and decisions about plantings. With the consent of the participants, the interview team took written notes and made an audio recording of each site visit. The written notes were the basis for the production of transcripts of the visits, together with site visit team observations. The audio recordings supplemented the written record in production of the transcripts. The interview transcripts were then coded for key attitudinal and behavioral variables (e.g., "awareness of metering", "drought-resistant planting") and the codes subjected to a simple frequency count followed by qualitative analysis of the context in which specific coded statements and behaviors took place. We performed all the analysis of the data without the aid of qualitative data analysis software and our analysis involved an emergent coding process, comparing interview data from each site visit, looking for patterns and themes that cut across the data.

\subsection{Focus Group Interviews}

For the focus group interviews, we contracted with Simi Marketing Group of Fresno to select a sample from our set of survey respondents for participation. The criterion for selection in one of three focus groups was socio-economic status based on income, with group one being $\$ 20-\$ 40,000$, group two $\$ 41-\$ 80,000$, and group three $\$ 80,000$ and above. Six individuals were selected for inclusion in each group and as compensation for their time, given a $\$ 50.00$ gift card for their participation. Demographically, each group contained Caucasian and Hispanic residents of the FCMA.

We used the survey instrument (Table S2) as the protocol for the focus group interviews, questioning each group about: yard size, current yard vegetation, how often they watered their yards, the amount of their monthly water bill, knowledge of the ongoing drought and municipal water 
policies, and whether the participants were interested in transforming their current yards into low water landscapes. Each focus group interview lasted one and a half hours, with a moderator to ask questions and keep the group on task, and two observers who audio recorded the interviews and took observation notes of the interactions between members of the group. There was little disagreement among the two observers in their real-time notes. We did not employ any computer-based approach to the qualitative analysis.

All procedures and protocols for the study were reviewed and approved by Fresno State University Institutional Review Board.

\section{Results}

The mixed-method research we employed offers the strengths of mail questionnaires combined with site visits and focus group interviews to provide a broader perspective on the overall issue. Analysis of the data we obtained involved a statistical examination of the survey data and a search for patterns and trends in behavior from the site visits and focus group comments to make the study more comprehensive. The results of these analyses identify a number of commonalities and differences even though the participation rates were low. The analysis of the responses indicates an interplay of social-structural, institutional, and cultural factors involved in influencing individual water use behaviors and landscape decision-making. Running a set of frequency distributions and bivariate correlations on responses to water and landscape use questions revealed some meaningful trends on the part of survey participants.

\subsection{Mail Questionnaire}

We received surveys from 63 of 74 sites, with 118 completed surveys and 63 returned as "undeliverable". If we exclude the undeliverable surveys, the response rate is $16 \%$. Mail surveys are known for having low response rates (often under 30\%), and despite the gift card incentive we offered for completion of the survey, and two follow up mailings, we were unable to improve the overall response. Figure 2 maps the survey participation by each zip code areas that includes 63 sites.

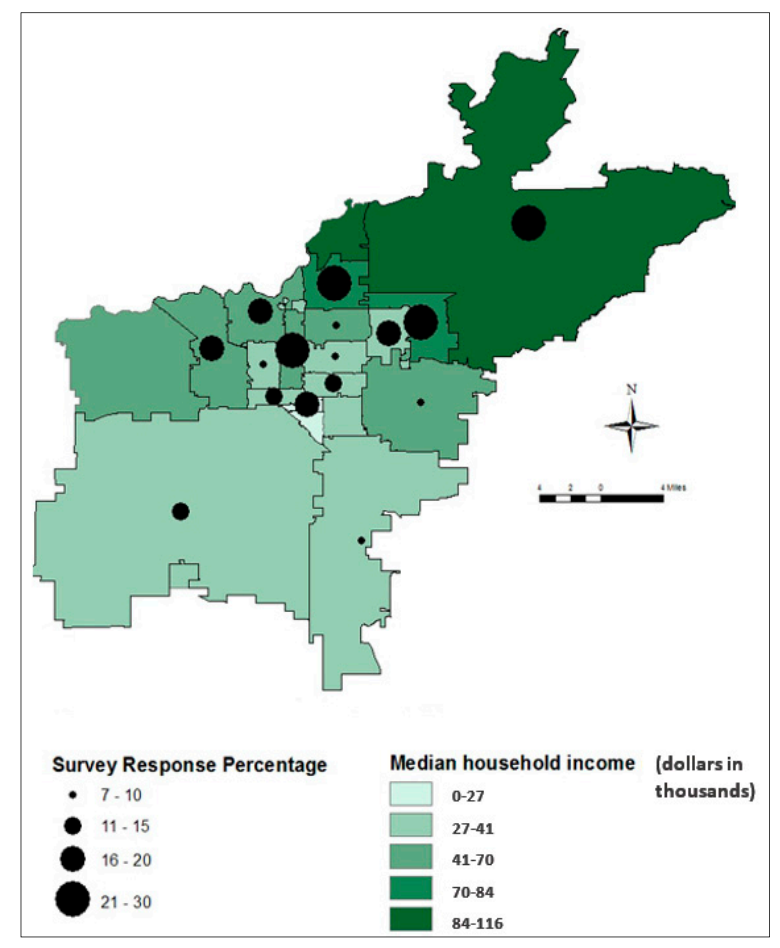

Figure 2. Survey participation by zip code areas (percentage). 
The results of the mail questionnaire are analyzed in four areas of inquiry; demographics, outdoor water use, water policies in the neighborhood, and decision-making involving water use. The details of the analysis are summarized below.

\subsubsection{Demographics}

Of the completed surveys we received, $86.7 \%$ of respondents lived in houses, with $75.2 \%$ being homeowners and $90.2 \%$ having properties with an estimated value of $\$ 100,000$ or more. In terms of demographics, $56.8 \%$ of respondents were Caucasian, and $50.5 \%$ had attained a bachelor's degree or greater for level of completed education.

The educational attainment of Fresno County residents and survey respondents are weakly negatively correlated. Fresno County shows a higher concentration of high-school and less-than-high-school graduates but survey respondents have at least some college degree in general (Figure 3).

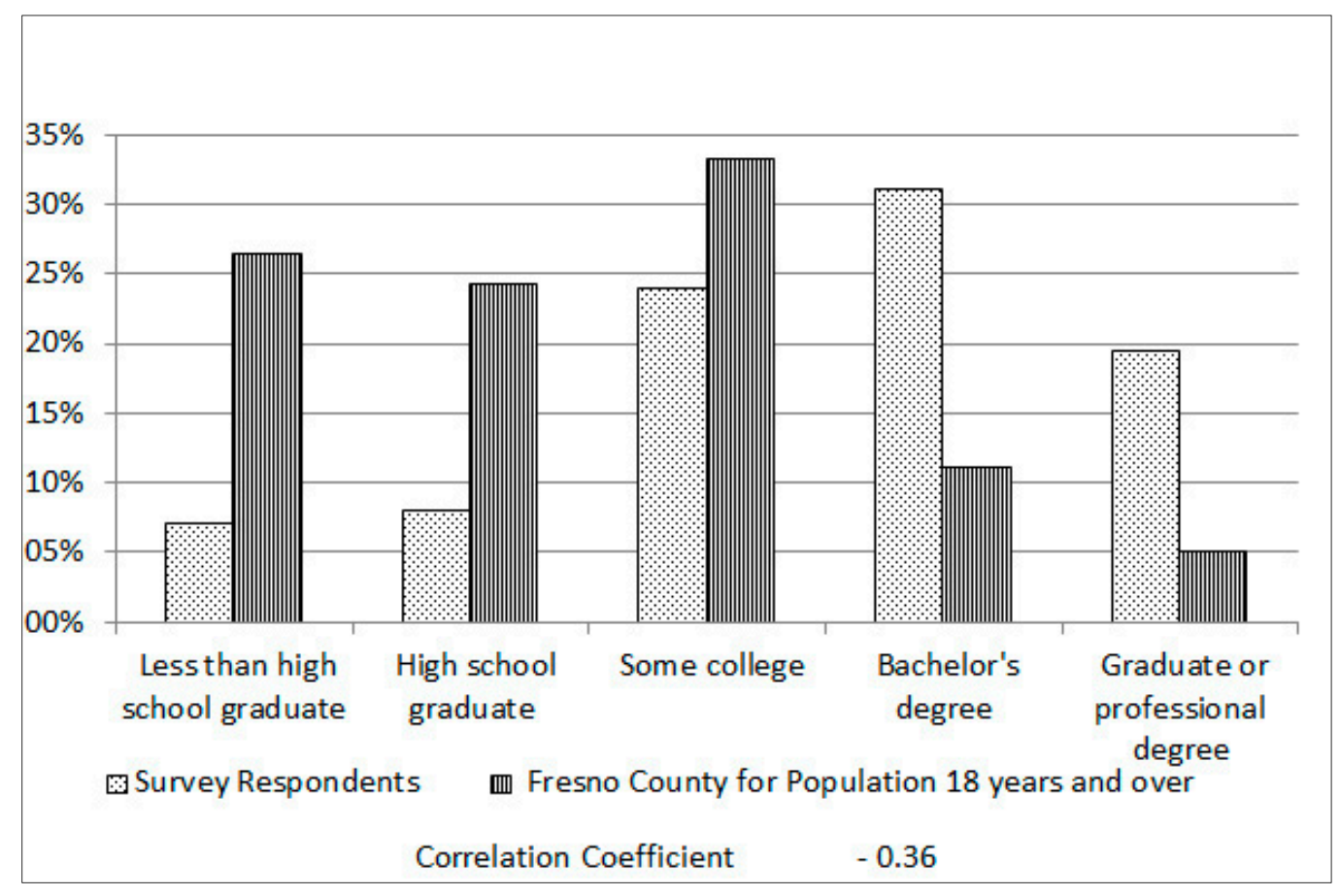

Figure 3. Educational attainment of survey respondents and Fresno County for population 18 years and over.

Over $28 \%$ of respondents reported being 65 or older, compared to $10 \%$ of the actual population in Fresno County. Eighteen percent of respondents reported being between 55 and 65, compared to $9.8 \%$ of the actual population, and 24\% reported being between 46 and 55 (12.5\%). Though Fresno County's population is young (with a median age of 30.7), the survey respondents are mainly over 46 years old.

Residents who reported high income participated in the survey at higher rates. The correlation between survey respondents' and Fresno County residents' income is strongly positive (Figure 4).

A majority of respondents preferred flowering and ornamental plants for their landscapes (54\% preferred either flowering, ornamental, or both). Only $10 \%$ of respondents reported having flowering, ornamental, and fruit- and vegetable-bearing plants in their yards. Educational attainment was positively correlated $\left(X^{2}=117.467, d F=78, P=0.003\right)$ with diversity of selection of household plantings (what types of vegetation homeowners chose to place in their landscapes). 


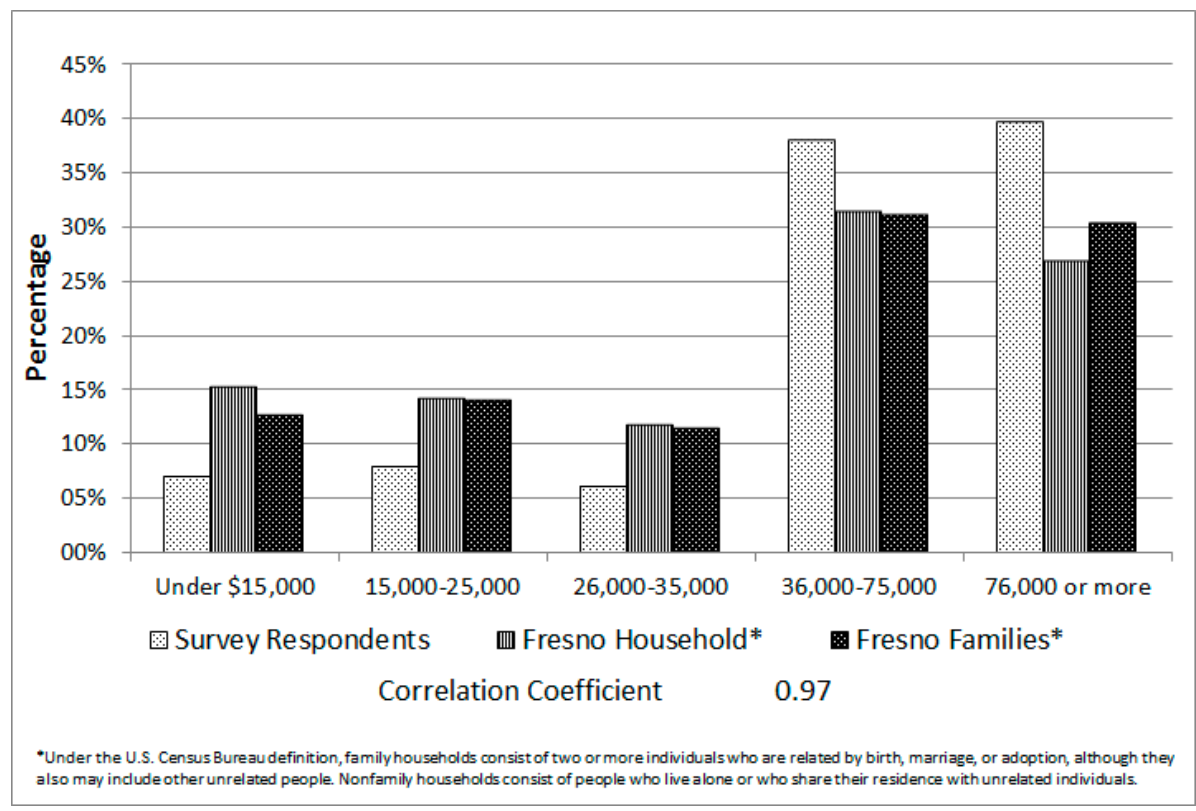

Figure 4. Income of survey respondents, Fresno households, and Fresno families.

\subsubsection{Outdoor Water Use}

While $85.8 \%$ of respondents self-reported compliance with municipal codes for watering lawns, over $76 \%$ estimated their outdoor watering to constitute $60 \%$ or less of their overall residential water use-this suggests a significant underestimate compared to the official municipal estimate that $70 \%$ of residential water use in the FCMA is for landscaping. Chi square analysis revealed that homeowners' use of landscaping companies to maintain their yards was significant in the choice of household plantings $\left(X^{2}=30.4, d F=13, P=0.004\right)$ and that educational attainment was significant with regards to saving water for economic reasons $\left(X^{2}=16.197, d F=6, P=0.013\right)$. Home property value was positively correlated with lawn watering frequency $(r=0.212, n=113, P=0.024)$, indicating that those homeowners with greater affluence were more likely to violate municipal water policies in order to maintain their landscapes.

A possible form of cultural inertia appeared within responses to questions regarding landscape use. Respondents were queried as to what activities they had performed within the past year with regards to water use and plantings.

Table 1 provides the percentage response rates to the questions posed. While a majority of respondents self-reported doing things to conserve water, an even greater number indicated they had not taken action to remove water-intensive plantings from their landscapes, nor planted drought-resistant, native species to aid in their water conservation efforts. Site visits provided more nuanced data, indicating that respondents were engaged in behaviors promoting water conservation not addressed by the survey questionnaire.

Table 1. Responses to questions involving water in the Fresno Clovis Metro Area $(n=118)$.

\begin{tabular}{l}
$\begin{array}{l}\text { Without looking up the answer, how much rainfall do you estimate the Fresno/Clovis area gets every year } \\
\text { on average? }\end{array}$ \\
\hline \begin{tabular}{cc}
$0-10$ inches/year & $38.9 \%$ \\
$11-20$ inches/year & $37.2 \%$ \\
\hline Within the last 12 months, have you tried to reduce water consumption for economic reasons? \\
\hline Questionnaire: & Yes $=54.5 \%$ \\
Site visit sample: & Yes $=50 \%$ \\
\hline
\end{tabular}
\end{tabular}


Table 1. Cont.

\begin{tabular}{|c|c|}
\hline \multicolumn{2}{|c|}{ Within the last 12 months, have you tried to reduce water consumption for environmental reasons? } \\
\hline Questionnaire: & Yes $=62.7 \%$ \\
\hline Site visit sample: & Yes $=57.1 \%$ \\
\hline \multicolumn{2}{|c|}{$\begin{array}{l}\text { Within the last } 12 \text { months, have you planted trees and other plants native to the San Joaquin Valley in } \\
\text { your yard? }\end{array}$} \\
\hline Questionnaire: & $\mathrm{No}=75.5 \%$ \\
\hline Site visit sample: & $\mathrm{No}=78.6 \%$ \\
\hline \multicolumn{2}{|c|}{$\begin{array}{l}\text { Within the last } 12 \text { months, have you removed trees and other plants from your yard that were } \\
\text { water intensive? }\end{array}$} \\
\hline Questionnaire: & $\mathrm{No}=80.0 \%$ \\
\hline Site visit sample: & $\mathrm{No}=75 \%$ \\
\hline
\end{tabular}

\subsubsection{Water Policies in the Neighborhood}

Fifty-three percent of residents reported having water meters (including both Fresno residents who had meters installed but not activated at the time of the survey and Clovis residents with active meters) while $49.2 \%$ indicated they were under some set of restrictions involving water use such as metering, and watering schedules. A follow-up question inquired as to whether infraction of those restrictions would be met with some form of penalty, to which $40.7 \%$ replied affirmatively. Twenty-three percent of respondents did not know whether there were penalties for violating water policies.

\subsubsection{Decision-Making Involving Water Use}

Another finding of interest revolved around residents' levels of confidence in organizational and institutional actors involved in water policy decision-making and the level of influence different groups and institutions had on their landscaping decisions (Table 2).

Table 2. Confidence in and influence of institutional actors $(n=118)$.

\begin{tabular}{|c|c|c|c|c|}
\hline \multicolumn{5}{|c|}{$\begin{array}{l}\text { How much confidence do you have in each of the following groups to make the best decisions for you and your area regarding } \\
\text { water use? }\end{array}$} \\
\hline \multirow[b]{2}{*}{ Confidence in: } & \multicolumn{4}{|c|}{ Confidence Level \% } \\
\hline & Great Deal & Some & Not Very Much & Very Little \\
\hline Neighborhood associations or civic groups & 6.8 & 28.0 & 10.2 & 17.8 \\
\hline Municipal government & 17.8 & 29.7 & 16.9 & 16.1 \\
\hline State government & 6.8 & 28.8 & 14.4 & 28.0 \\
\hline Federal government & 6.8 & 22.0 & 10.2 & 36.4 \\
\hline You and your family & 52.5 & 26.3 & 6.8 & 3.4 \\
\hline Your neighbor(s) & 14.4 & 34.7 & 16.9 & 19.5 \\
\hline \multicolumn{5}{|c|}{ How much do each of these groups influence your use of water for landscaping or other outdoor uses? } \\
\hline & \multicolumn{4}{|c|}{ Influence level \% } \\
\hline Influence from: & Great Deal & Some & Not Very Much & Very Little \\
\hline Family members & 17.8 & 26.3 & 9.3 & 16.9 \\
\hline Neighborhood association rules & 7.6 & 9.3 & 4.2 & 7.6 \\
\hline City plantings and watering on public lands (e.g., parks) & 8.5 & 14.4 & 11.9 & 14.4 \\
\hline Apartment complex managers & 8.5 & 4.2 & 4.2 & 3.4 \\
\hline Homeowner's association & 3.4 & 8.5 & 5.1 & 3.4 \\
\hline Landlord & 6.8 & 7.6 & 4.2 & 5.1 \\
\hline Neighbors & 7.6 & 20.3 & 10.2 & 28.8 \\
\hline \multicolumn{5}{|c|}{ Most influential group on resident's use of water for landscaping and other outdoor uses: } \\
\hline Family members & & $39.8 \%$ & & \\
\hline Neighbors & & $14.4 \%$ & & \\
\hline \multicolumn{5}{|c|}{ Second most influential group on resident's use of water for landscaping and other outdoor uses: } \\
\hline Neighbors & & $34.7 \%$ & & \\
\hline Family members & & $11.0 \%$ & & \\
\hline City plantings & & $11.0 \%$ & & \\
\hline
\end{tabular}


Confidence and influence levels were low for governmental agencies but greater for family members and neighbors, especially in terms of influence. A proxemic effect appears to be at work with regards to both confidence and influence for respondents. Families and neighbors have greater proximity and access to residents than do institutional actors such as governmental agencies, thus explaining in part the indication of family members and neighbors as being the most influential actors on respondents' water use behaviors and landscape decisions.

Robbins [57] (pp. 110-112) describes how Kingberry Court residents felt a sense of moral responsibility to their neighbors to keep their lawns healthy and green, even if it means applying chemicals they suspect are dangerous. Yet, they also reported that they rarely talked to their neighbors about their lawns and yards. It is possible that a similar dynamic is causing an under-reporting of neighbor influence in the survey: respondents may not interact directly with neighbors on landscape and watering, and hence they do not recognize neighbors as influential when asked. However, our site visits, like Robbins' interactions with his Kingberry Court resident, revealed that water use is intimately tied to neighbors' landscaping activities and perceived expectations (see below, "Structural Effects and Neighborhood Regulation").

Regarding residential perceptions of water issues, $47 \%$ of respondents agreed that "the price of water restricts what I want to do with my yard". "Individuals should take responsibility for the environment around them", produced a $92 \%$ agreement rate among respondents. "I do not have time to conserve water", was a statement with which $78 \%$ disagreed. Eighty-five percent agreed with the statement, "Storm water is a valuable resource that should be reused", while $66 \%$ disagreed with, "I really have not thought much about cutting down our use of water". The last statement, "Individuals should take responsibility for improving their communities", served as a proxy for political attitudes and $89.8 \%$ of respondents agreed with it.

\subsection{Site Visits}

Site visits with ten college-educated homeowners provide further insights into some of the attitudes and actions behind the larger survey responses. Even though the participation rate was low, the ten participants provided enough information to begin to explore the individual characteristics and preferences that influence the use of water in the FCMA.

\subsubsection{Conservation: Preference and Behavior}

The gap between what people say about water conservation in their yards and what they actually do was a strong, consistent theme in the site visits (the gap between preference and behavior is well-established in the urban ecology literature; see $[55,57,58])$. Most participants felt it was important for them to reduce water use in their yards, either because they said they cared about a perceived water shortage or about the cost implications of impending water metering in Fresno. However, only five participants had acted to reduce water usage. Two of them installed drip irrigation and two planted drought-resistant plants (like rosemary and lantana). Two planted a water-intensive variety of grass (fescue tall) mistakenly believing it required little water. Moreover, nearly all of the participants who professed concern about water usage could not identify the water requirements of existing or planned landscape features, and in some cases, had recently planted species with high water requirements.

All participants had criteria other than water conservation in mind when landscaping their yards, and concern for water use was also easily trumped by function and aesthetics in peoples' landscaping choices. Five participants had acted on their professed concern for limiting their outdoor water use. However, optimism about this finding must be tempered with the realization that the site visit participants likely self-selected for greater water-use awareness, and that some of their actions did not actually result in less water intensive plantings.

On the individual survey, for the question "have you tried to reduce water consumption for economic reasons within the last 12 months?", half the homeowners in the educational range of the site visit participants answered "yes" and half answered "no" $(n=56)$. On the question "Have you tried to 
reduce water consumption for environmental reasons within the last 12 months?", 57\% answered "yes" and $41 \%$ answered "no". These results mirror the 50\% (five of 10) of site visit participants who showed evidence of acting on a desire to save water. However, the visits reveal that in some of the survey cases, the actions taken may be misperceived by the respondent to be saving water (e.g., planting fescue). Also, the site visit participants undertook water-reducing actions that were quite modest compared to other actions in their yards that tended to be water intensive. Hence, interpretations of survey responses that indicate action to reduce water use warrant caution.

The survey finding for the question "Have you removed trees and other plants from your yard that were water intensive within the last 12 months?" was not borne out by the site visits. Twenty-four percent of homeowners in the educational range of the site visit participants answered "yes" to this question, yet not one of the site visit participants showed evidence of this kind of action. Either we simply missed the "yes" respondents in the site visit sample, or the "yes" responses to this question involve some action that, on the ground, is not what the survey respondents thought it was.

\subsubsection{Aesthetics}

All ten participants showed evidence of having acted on aesthetic concerns in their landscaping choices. Echoing numerous other studies, aesthetic concerns were by far the most important driver of behavior for the site visit participants [13,58]. This trend is also reflected in survey results regarding choice of plantings, as $90 \%$ of respondents reported having flowering and/or ornamental plants in their yards, indicating a preference for plants with visual or aromatic appeal rather than plants that provide some form of sustenance.

We see evidence of two significant types of aesthetic concerns. One type is located at the level of the individual plantings, revolving around visual or aromatic appeal. The other type of aesthetic concern involves a more comprehensive attempt by some participants to create a particular kind of highly personal, highly valued outdoor experience in their yards. These participants tended to have an emotive, sometimes nostalgic vision of the kind of landscape they wanted to inhabit. Kin ties and family memories—either existing or hoped for-figured importantly in these cases.

\subsubsection{Function}

Function or utilitarian value was also a very important driver of landscaping behavior, with evidence of nine of the site visits for behavior based on perceived function of the landscape. Fruit trees, for example, which four participants had deliberately planted, were usually mentioned in conjunction with their produce.

The participants, especially those with young children, were also sensitive to the uses of their lawns. Concern for children's activities featured in other kinds of landscape plans. Convenience and time-and-effort-saving also emerged as important themes in several site visits.

\subsubsection{Cost/Benefit Uncertainties}

The survey respondents who agreed to host a site visit are likely a self-selected group that is relatively more well-informed about water use policy than their peers. The impending start of water metering came up repeatedly. However, the participants consistently expressed uncertainty about how metering would affect their bills.

The most common sentiment was uncertainty about whether the costs of water-saving efforts would result in appreciable benefits. Such observations from the site visit participants indicate little in the way of support for a treadmill of consumption [31] explanation for water use behaviors and landscaping practices.

\subsubsection{Structural Effects and Neighborhood Regulation}

Most of the participants had significant landscaping features of their properties already in place when they bought their houses. Hence, there is much about these residential landscapes upon which 
the owners had limited initial choice, as existing features (landscape legacies) exerted an influence on later choices. To a degree (as we gathered baseline data and thus did not have a measure of whether new plantings result in a net increase of water usage), this could be interpreted as both a structural effect and a response to the pressures exerted by residents in neighborhoods with particular expectations about landscape (see [57]). While social considerations, like status, were likely in play for some of the participants, they were not raised explicitly on any of the site visits.

\subsection{Focus Group Interviews}

Several themes and patterns emerged from the three focus group interviews:

- All participants had grass yards, and asserted that such yards were best for children (to play upon, etc.).

- Eleven of the 12 participants in the first two groups did not have an aesthetic appreciation of low water landscaping.

- Seventeen out of 18 participants were reluctant to change from turfgrass lawns to low water landscaping, but did express an interest in attaining information on water metering, low water use plants, the water savings that xeriscaping would provide, and what incentives the state or city would provide to change their lawns. Those 17 indicated they would switch to low water landscaping if the price of water became unaffordable due to metering.

- None of the participants expressed interest in wildlife or environmental conservation, but over one third expressed fear regarding an increase in the presence of what they described as hostile insects (i.e., wasps, bees, and ants).

\section{Discussion}

With this exploratory study, we find evidence that structural conditions combined with cultural inertia and perceptions of water pricing are driving domestic landscape and related water use patterns. We reach this conclusion through an analysis of both the survey and the site visit data. In short, existing single-family residence dwellers are living in neighborhoods and presiding over domestic landscapes that are relatively water-intensive because the landscapes were established under a flat-rate water-pricing system coupled with a cultural context in which conservation provided little or no incentive for altering behavior. In this context, in spite of frequent pronouncements of concern for water conservation, residential landscape managers made decisions based largely on aesthetics and function, with concerns about neighborhood norms and expectations serving as a major background condition. Water metering, which was completed in 2013 in the Fresno residential areas of the FCMA, is spurring some interest in altering domestic landscapes. At the time of the interviews, most site visit participants cited knowledge of impending metering as one incentive they had for at least contemplating change. However, the current tiered price system does not impose particularly high costs for intensive water usage, since the per gallon pricing was calculated to keep the average monthly cost relatively unchanged for the average consumer. Hence, residents, faced with the structure of existing landscapes, are uncertain that changes will yield benefits that outweigh their costs. Those who did make changes to their landscapes for economic or environmental reasons tended to make small changes, some of which were actually inconsistent with reducing water usage. Even if cost-benefit and informational challenges are overcome, residents still lack a clear cultural mandate for making changes that result in less water use, especially when faced with existing water-intensive landscapes. When managing their domestic landscapes, the site visit participants largely maintained their landscapes with little regard for impending metering, as decisions about change were based largely on aesthetics and function of plantings. Water conservation is simply not an important criterion for decision-making among residents of single-family dwellings in the Fresno-Clovis Metropolitan Area.

We find evidential support for status honor [32-35], affluence and increased resource consumption [14-22], structural conditions [29,30], and cultural inertia [43,44] based explanations for 
water usage and landscaping decisions. We did not find evidential support for landscape legacy $[46,47]$ nor for political economy network [57] based explanations of water usage and landscaping decisions.

We also find some support for the role of personal identity formation and status concerns in driving water use. The survey revealed that home property value was positively correlated with lawn watering frequency (weakly significant with $P=0.024$ ), suggesting that more affluent homeowners were more likely to violate municipal water policies in order to maintain their landscapes. While status concerns were hardly broached in the site visits, they did reveal that aesthetics were a powerful influence on landscape choices, usually at the expense of water conservation. If aesthetic concerns (how one's yard looks) are linked to status, then this finding supports that of the survey, with the more affluent using more water to maintain normatively more appealing landscapes that are also more water intensive. However, lifestyle and personal identity formation complicates a simple analysis based on status concerns. Several participants were pursuing comprehensive visions of emotionally powerful landscapes. As detailed below, with one exception, these tended to be water-intensive landscapes, lending added weight to the conclusion that cultural inertia combined with structural constraints-in this instance, tangled up with personal identity-are the most powerful explanations for the landscape and water use patterns observed.

The social survey reveals some of the complexity involved in individual water use decisions and behaviors. Respondents indicated family and neighbors as being influential in their water use decision-making, revealing proximity and frequency of contact as factors of influence. Relatedly, decisions involving plantings within residential landscapes indicated a significant degree of influence by institutional actors.

Adding to this complexity, site visit data conveyed the importance of aesthetics and cultural inertia on landscape decision-making. As revealed in their personal narratives, residents chose homes in some cases based on existing landscapes (planting decisions made by previous owners) that they found aesthetically pleasing. Others felt the cost in time, energy, and financial resources to be a barrier to transforming their landscapes along the lines of environmental conservation/sustainability.

Given the structural conditions combined with cultural inertia as drivers of domestic landscaping and related water use patterns, transformation of landscapes and water usage involves a level of complexity that goes beyond the factors conveyed in socio-ecological systems (SES) approaches. The implications of this complexity pose some potential issues with regards to the interactions between individual households and institutional actors in matters of water usage and landscaping.

The results of this study pose some interesting challenges for governmental entities that seek to implement policies that are environmentally sustainable and for organizations that promote ecologically-minded landscaping practices in urban residential communities. The survey results and site visits indicate a lack of confidence in governmental entities concerning water policies and how they will impact the citizenry. Promotion and implementation of sustainable water use practices will require not only environmental education for the citizenry, but a tailoring of information for environmental educational initiatives that addresses the particularities of individual neighborhoods and communities. Our results suggest that a singular approach may produce resistance to landscape transformations along sustainable lines.

The 74 sites selected for the social surveys also formed the core sampling sites for a study of tree species diversity and urban forest cover [63]. These sites have now become core sites for long-term monitoring by the Fresno Bird Count, and related studies [65]. Co-location of sampling sites for biodiversity and social surveys will allow for a more expansive study examining coupled social-ecological dynamics in a spatially explicit framework using GIS, and to monitor changes in both the social and ecological components with the now-metered residences. This connection is especially important to establish considering that individual household analysis is only part of the ULTRA-FACES and should be integrated into the broader project.

Actions taken at the household level influence the overall landscape matrix of the city, in turn affecting the diversity of other species occupying urban habitats. The complex social and psychological 
factors that influence water use and landscaping decisions have a direct effect on urban plant diversity [47]. Indeed, tree species diversity at any given site in the FCMA is strongly influenced by neighborhood median family income, home property value, and irrigation level [63]. In turn, the diversity of bird species and of the ecological niches they occupy are also strongly influenced by neighborhood socioeconomic status and irrigation levels [62]. That study also found that some kinds of bird species-insectivores, and native species-are particularly sensitive to irrigation levels. Here we found that attracting birds to the yard is an important function influencing the planting decisions of at least some homeowners, while others are interested in conserving water and planting native species. Lack of information about native species, and of the water requirements of available lawn grass and garden plant choices, are important constraints on homeowner choices that influence overall biodiversity. Strategies to enhance biodiversity conservation in urban areas must address this knowledge gap and provide better access to, and promotion of, information about ecologically appropriate planting and landscaping choices.

If water conservation is a priority for urban environments, then institutional actors as well as individual households must be involved in promoting it. For example, given the influence of landscaping companies on choice of plantings in residents' yards, one can see the need to involve institutional actors such as landscaping companies and plant nurseries in the effort. This effort will entail the promotion of native plantings specific to particular environments, and the promotion of those indigenous species as having an aesthetic that should be desired by residents living in those particular environments. Such advocacy may run afoul of the ideology of residential property development that promotes a rather singular form of home construction and landscaping. Transforming urban landscapes along lines of environmental sustainability will require a model of decision-making that incorporates consensus building rather than the top-down managerial model of decision-making that now seems predominant in our social institutions.

Supplementary Materials: The following are available online at www.mdpi.com/2071-1050/9/10/1746/s1, Table S1: Survey instrument: list of questions included in the mail questionnaire. Table S2: Focus group interview protocol: list of questions posed to each group to structure the conversation.

Acknowledgments: This paper is based on research funded by the National Science Foundation (ULTRA-Ex Award \# 0949036), a Toyota TogetherGreen Fellowship (awarded to Kaberi Kar Gupta) from the National Audubon Society, and the College of Science \& Mathematics, California State University, Fresno. We thank collaborators of the ULTRA-FACES project for discussions that helped develop the conceptual framework and overall context of this study, in particular Mary Cadenasso, John Bushoven, and Lara Triona. We thank Xioaming Yang for managing the ULTRA-FACES GIS database. We thank the following students who participated in the research: Seth T. Reid, Bradley Schleder, Jesse Mendiola, Melissa Sarno, Amer Naik, Jennifer Phillips, Kelsey Francone, Megan Bailey, and Brian Cortes. We also thank Christopher Trisos for feedback and critique of earlier versions of this manuscript.

Author Contributions: Madhusudan Katti, Andrew Rhys Jones, and Derya Özgöç Çağlar conceived and designed the study. Jones conducted the social surveys, Henry D. Delcore conducted the site visits, and Kaberi Kar Gupta conducted the focus group interviews. Katti, Jones, and Çağlar analyzed the data. All five co-authors wrote the paper collaboratively.

Conflicts of Interest: The authors declare no conflict of interest. The funding sponsors had no role in the design of the study; in the collection, analyses, or interpretation of data; in the writing of the manuscript, and in the decision to publish the results.

\section{References}

1. Kundzewim, Z.W. Some for all, forever-Sustainable development and management of water resources. Int. J. Sustain. Dev. World Ecol. 2001, 8, 290-298. [CrossRef]

2. Diamantini, C.; Zanon, B. Planning the urban sustainable development: The case of the plan for the province of Trento, Italy. Environ. Impact Assess. Rev. 2000, 20, 299-310. [CrossRef]

3. Deniz, B.; Eşbah, H.; Küçükerbaş, E.V.; Şirin, U. Analysis of vegetation structure in urban land uses: Case of the City of Aydın. Ekoloji 2008, 17, 55-64. [CrossRef]

4. Dong, R.; Xu, H.; Gou, Y.; Fu, X.; Gang, W. Analysis of land-use scenarios for urban sustainable development: A case study of Lijiang City. Int. J. Sustain. Dev. World Ecol. 2011, 18, 486-491. [CrossRef] 
5. Alig, R.J.; Kline, J.D.; Lichtenstein, M. Urbanization on the US landscape: Looking ahead in the 21st century. Landsc. Urban Plan. 2004, 69, 219-234. [CrossRef]

6. Hope, D.; Gries, D.; Warren, P.; Katti, M.; Stuart, G.; Oleson, J.; Kaye, J. How do humans restructure the biodiversity of the Sonoran Desert? In Connecting Mountain Islands and Desert Seas: Biodiversity and Management of the Madrean Archipelago II; Gottfried, G.J., Ed.; USDA Forest Service, Rocky Mountain Research Station: Tucson, AZ, USA, 2004; pp. 189-194.

7. Grimm, N.B.; Faeth, S.; Golubiewski, N.; Redman, C.; Wu, J.; Bai, X.; Briggs, J. Global change and the ecology of cities. Science 2008, 319, 756-760. [CrossRef] [PubMed]

8. Graymore, M.L.M.; Wallis, A.M. Water savings or water efficiency? Water-use attitudes and behaviour in rural and regional areas. Int. J. Sustain. Dev. World Ecol. 2010, 17, 84-93. [CrossRef]

9. Stead, D. Urban planning, water management and climate change strategies: Adaptation, mitigation and resilience narratives in the Netherlands. Int. J. Sustain. Dev. World Ecol. 2014, 21, 15-27. [CrossRef]

10. Tyler, M.E.; Quin, M. A social-spatial approach to ecological governance. Int. J. Interdiscip. Soc. Sci. 2010, 5, 73-86. [CrossRef]

11. Grimm, N.B.; Grove, J.M.; Pickett, S.T.A.; Redman, C.L. Integrated approaches to long-term studies of urban ecological systems. BioScience 2000, 50, 571-584. [CrossRef]

12. Pickett, S.T.A.; Cadenasso, M.L.; Grove, J.M.; Nilon, C.H.; Pouyat, R.V.; Zipperer, W.C.; Costanza, R. Urban ecological systems: Linking terrestrial ecological, physical, and socioeconomic components of metropolitan areas. In Urban Ecology: An International Perspective on the Interaction between Humans and Nature; Marzluff, J.M., Shulenberger, E., Endlicher, W., Alberti, M., Bradley, G., Ryan, C., Simon, U., ZumBrunnen, C., Eds.; Springer: New York, NY, USA, 2008; pp. 99-122.

13. Aksoy, Y. Examining the ecological quality of Küçükçekmece district parks in İstanbul in terms of permeability and natural vegetation. Ekoloji 2010, 19, 181-189. [CrossRef]

14. Berk, R.A.; Cooley, T.F.; LaCivita, C.J.; Parker, S.; Sredl, K.; Brewer, M. Reducing consumption in periods of acute scarcity: The case of water. Soc. Sci. Res. 1980, 9, 99-120. [CrossRef]

15. Hamilton, L.C. Saving water: A causal model of household conservation. Sociol. Perspect. 1983, 26, 355-374. [CrossRef]

16. Mainieri, T.; Barnett, E.G.; Valdero, T.R.; Unipan, J.B.; Oskamp, S. Green buying: The influence of environmental concern on consumer behavior. J. Soc. Psychol. 1997, 137, 189-204. [CrossRef]

17. Vickers, A. Handbook of Water Use and Conservation; Water Plow Press: Amherst, MA, USA, 2001.

18. Princen, T.; Maniates, M.; Conca, K. Confronting Consumption; The MIT Press: Cambridge, MA, USA, 2002.

19. Corral-Verdugo, V.; Bechtel, R.B.; Frijo-Sing, B. Environmental beliefs and water conservation: An empirical study. J. Environ. Psychol. 2003, 23, 247-257. [CrossRef]

20. Hanak, E.; Browne, M.K. Linking housing growth to water supply. J. Am. Plan. Assoc. 2006, 72, $154-166$. [CrossRef]

21. Coleman, J.S. Foundations of Social Theory; Harvard University Press: Cambridge, MA, USA, 1990.

22. Wallace, R.; Wolf, A. Contemporary Sociological Theory: Continuing the Classical Tradition, 3rd ed.; Prentice Hall: Upper Saddle River, NJ, USA, 1991.

23. Smith, A. An Inquiry into the Nature and Causes of the Wealth of Nations; William Strahan: London, UK, 1776.

24. De Oliver, M. Attitudes and inaction: A case study of the manifest demographics of urban water conservation. Environ. Behav. 1999, 31, 372-394. [CrossRef]

25. Jowsey, E. The changing status of water as a natural resource. Int. J. Sustain. Dev. World Ecol. 2012, 19, 433-441. [CrossRef]

26. Corral-Verdugo, V.; Frias-Armenta, M.; Perez-Urias, F.; Orduna-Cabrera, V.; Espinoza-Gallego, N. Residential water consumption, motivation for conserving water and the continuing tragedy of the commons. Environ. Manag. 2002, 30, 527-535. [CrossRef]

27. Catenazzo, G.; D’Urso, J.; Fragnière, E.; Tuberosa, J. Influences of Public Ecological Awareness and Price on Potable Water Consumption in Geneva. In Climate Change and the Sustainable Use of Water Resources. Climate Change Management; Leal Filho, W., Ed.; Springer: Berlin, Germany, 2012.

28. Morehouse, B.J. Climate impacts on urban water resources in the southwest: The importance of context. J. Am. Water Resour. Assoc. 2000, 36, 265-277. [CrossRef] 
29. Tinker, A.; Bame, S.; Burt, R.; Speed, M. Impact of “Non-Behavioral Fixed Effects" on Water Use: Weather and Economic Construction Differences on Residential Water Use in Austin, Texas. EGJ. 2005. Available online: http:/ / escholarship.org/uc/item/7rh33286 (accessed on 26 September 2017).

30. Corbella, H.M.; Pujol, D.S. What lies behind domestic water use? A review essay on the drivers of domestic water consumption. Bol. R. Acad. B. Artes San Fernando 2009, 50, 297-314.

31. Bell, M. An Invitation to Environmental Sociology, 3rd ed.; Pine Forge Press: Thousand Oaks, CA, USA, 2009.

32. Weber, M. Class, status and party. In From Max Weber: Essays in Sociology; Gerth, H., Mills, C.W., Eds.; Routledge and Kegan Paul: London, UK, 1924.

33. Simmel, G. Fashion. In On Individuality and Social Forms; Simmel, G., Ed.; University of Chicago Press: Chicago, IL, USA, 1971; pp. 294-323.

34. Veblen, T. The Theory of the Leisure Class; MacMillan Publishers: London, UK, 1899.

35. Simmel, G. The metropolis mortal life. In On Individuality and Social Forms; Simmel, G., Ed.; University of Chicago Press: Chicago, IL, USA, 1971; pp. 815-823.

36. Hornig, K.H. Social structure, life-styles and man-object relationships. In Consumer Behavior and Environmental Quality; Uusitalo, L., Ed.; Ashgate Publishing: Farnham, UK, 1983; pp. 17-26.

37. Galbraith, J.K. The Culture of Contentment; Penguin Press: London, UK, 1993.

38. Syme, G.J.; Shao, Q.; Po, M.; Campbell, E. Predicting and understanding home garden water use. Landsc. Urban Plan. 2004, 68, 121-128. [CrossRef]

39. Dietz, T.; Stern, P.C.; Guagnano, G.A. Social structural and social psychological bases of environmental concern. Environ. Behav. 1998, 30, 450-471. [CrossRef]

40. Björklund, G.; Connor, R.; Goujon, A.; Hellmuth, M.; Moriarty, P.; Rast, W.; Warner, K.; Winpenny, J. Demographic, economic and social drivers. In World Water Assessment Programme. The United Nations World Water Development Report 3: Water in a Changing World; UNESCO: Paris, France, 2009.

41. Kurz, T. The psychology of environmentally sustainable behavior: Fitting together pieces of the puzzle. Anal. Soc. Issues Public Policy 2002, 2, 257-278. [CrossRef]

42. Domene, E.; Sauri, D. Urbanisation and water consumption: Influencing factors in the metropolitan region of Barcelona. Urban Stud. 2006, 43, 1605-1623. [CrossRef]

43. Zárate, M.A.; Shaw, M.; Marquez, J.A.; Biagas, D. Cultural inertia: The effects of cultural change on intergroup relations and the self-concept. J. Exp. Soc. Psychol. 2012, 48, 634-645. [CrossRef]

44. Wuthnow, R. Democratic renewal and cultural inertia: Why our best efforts fall short. Sociol. Forum 2005, 20, 343-367. [CrossRef]

45. Chapman, T. Smoke and mirrors: The influence of cultural inertia on social and economic development in a polycentric urban region. Urban Stud. 2011, 48, 1037-1057. [CrossRef]

46. Foster, D.; Swanson, F.; Aber, J.; Burke, I.; Brokaw, N.; Tilman, D.; Knapp, A. The importance of land-use legacies to ecology and conservation. BioScience 2003, 53, 77-88. [CrossRef]

47. Acar, C.; Sarı, D. Evaluation of plant species in urban residential landscapes based on their characteristics for landscape preferences: A sample of Trabzon City. Ekoloji 2010, 19, 173-180. [CrossRef]

48. Kelly, P.A.; Phillips, S.E.; Williams, D.F. Documenting ecological change in time and space: The San Joaquin Valley of California, in Mammalian Diversification. In Chromosomes to Phylogeography (A Celebration of the Career of James L. Patton); Lacey, E., Myers, P., Eds.; University of California Press: Berkeley, CA, USA, 2005.

49. Boone, C.G.; Cadenasso, M.L.; Grove, J.M.; Schwarz, K.; Buckley, G.L. Landscape, vegetation characteristics, and group identity in an urban and suburban watershed: Why the 60s matter. Urban Ecosyst. 2010, 13, 255-271. [CrossRef]

50. Jenerette, G.D.; Harlan, S.L.; Stefanov, W.; Martin, C. Ecosystem services and urban heat riskscape moderation: Water, green spaces, and social inequality in Phoenix, USA. Ecol. Appl. 2011, 21, 2637-2651. [CrossRef] [PubMed]

51. Giddens, A. Modernity and Self-Identity; Polity Press: Cambridge, MA, USA, 1991.

52. Beck, U. Risk Society: Towards a New Modernity; Sage Publications: London, UK, 1992.

53. McCracken, G. Culture and Consumption: New Approaches to the Symbolic Character of Consumer Goods and Activities; Indiana University Press: Bloomington, IN, USA, 1988. 
54. Shove, E.; Warde, A. Inconspicious consumption: The sociology of consumption, lifestyles and the environment. In Sociological Theory and the Environment: Classical Foundations, Contemporary Insights; Dunlap, R.E., Frederick, H.B., Dickens, P., Gijswijt, A., Eds.; Rowan \& Littlefield Publishers: Lanham, MD, USA, 2002.

55. Larsen, L.; Harlan, S.L. Desert dreamscapes: Residential landscape preference and behavior. Landsc. Urban Plan. 2006, 78, 85-100. [CrossRef]

56. Grove, J.M.; Troy, A.R.; O’Neil-Dunne, J.P.M.; Burch, W.R., Jr.; Cadenasso, M.L.; Pickett, S.T.A. Characterization of households and its implications for the vegetation of urban ecosystems. Ecosystems 2006, 9, 578-597. [CrossRef]

57. Robbins, P. Lawn People: How Grasses, Weeds, and Chemicals Make Us Who We Are; Temple University Press: Philadelphia, PA, USA, 2007.

58. Cook, E.M.; Hall, S.J.; Larson, K.L. Residential landscapes as social-ecological systems: A synthesis of multi-scalar interactions between people and their home environment. Urban Ecosyst. 2012, 15, $19-52$. [CrossRef]

59. Goffman, E. The Presentation of Self in Everyday Life; Anchor Books: New York, NY, USA, 1959.

60. City of Fresno. Water Conservation \& Landscaping. Available online: https://www.fresno.gov/ publicutilities / water-conservation-landscaping/ (accessed on 31 August 2016).

61. Hanak, E.; Mount, J.; Chappelle, C.; Lund, J.; Medellín-Azuara, J.; Moyle, P.; Seavy, N. What if California's Drought Continues? Public Policy Institute of California. Available online: http:/ / www.ppic.org/content/ pubs/report/R_815EHR.pdf (accessed on 26 September 2017).

62. Schleder, B.W. Residential Irrigation as a Driver of Urban Bird Community Structure. Master's Thesis, California State University, Fresno, CA, USA, 2010.

63. Reid, S.T. Ecological and Social Drivers of Tree Species Diversity and Distribution in Urban Habitats of the Central Valley of California. Master's Thesis, California State University, Fresno, CA, USA, 2011.

64. Bernard, H.R. Research Methods in Anthropology: Qualitative and Quantitative Approaches, 5th ed.; AltaMira Press: Lanham, MD, USA, 2011.

65. Slonka, S. The Effects of Changing Water Availability on Bird Communities in a California Urban Landscape. Master's Thesis, California State University, Fresno, CA, USA, 2016. 